ESTUDIOS 



\section{1. \\ Derecho civil}



Revista de Derecho

de la Pontificia Universidad Católica de Valparaíso XXIX (Valparaíso, Chile, $2^{\text {do }}$ Semestre de 2007)

[pp. 35-60]

\title{
LA CONSENSUALIZACIÓN DE LOS CONTRATOS REALES*
}

\author{
[The Transformation of the Real Contracts to Consensual Contracts]
}

\author{
Alejandro Guzmán Brito** \\ Pontificia Universidad Católica de Valparaíso
}

\begin{abstract}
RESUMEN
Existe una tendencia moderna a abolir la categoría del contrato real y a reemplazar sus actuales tipos específicos por sendos contratos consensuales. El trabajo expone los orígenes de tal tendencia y sus manifestaciones legislativas y la critica fundado en que el reemplazo ofrece problemas insolubles a la dogmática y por razones práctica.

Palabras clave: Contrato real - Contrato consensual - Abolición del contrato real.

Abstract

There is the modern tendency to abolish the category of the real contract and replace its actual specific types for two consensual contracts. This work presents the roots of that tendency and its legal manifestation and criticises it based on that the replacement offers unsolvable problems to the dogmatic aspect and also for practical reasons.

KeYwords: Real contract - Consensual contract - Abolition of the real contract.

* El presente trabajo también aparecerá en un homenaje que se prepara en honor del jurista peruano Fernando de Trazegnies. La ocasión de elaborarlo me fue ofrecida por la proposición hecha en Chile de sustituir los ahí vigentes contratos reales por otros consensuales, formulada por la profesora Solange Doyharçabal, en un informe titulado "Estudio sobre la conveniencia de mantener o no la categoría del contrato real en el Código Civil chileno" (2006), encargado por la Comisión Académica de Reformas a los Código Civil y de Comercio, la cual me encomendó, a su vez, hacerle un comentario, que en buena parte nutre esta colaboración, con las necesarias adaptaciones al Derecho peruano.

** Catedrático de la Facultad de Derecho de la Pontificia Universidad Católica de Valparaíso. Dirección postal: Avda. Brasil 2950, Valparaíso, Chile. Correo electrónico: aguzman@ucv.cl
\end{abstract}




\section{LA ABOLICIÓN DEL CONTRATO REAL \\ EN EL “CÓDIGO CIVIL” PERUANO DE 1984}

Entre los códigos civiles últimamente emitido en América está el del Perú de 1984. Éste conoce, como regla general, el tipo consensual de contratos y, por excepción, el tipo formal o solemne. Tal es el sentido de su artículo 1352: "Los contratos se perfeccionan por el consentimiento de las partes, excepto aquellos que, además, deben observar la forma señalada por la ley bajo sanción de nulidad". Desconoce, en consecuencia, el tipo de contrato que en la tradición romanística es llamado real, y entendido como aquel cuya perfección exige, además del consentimiento mutuo de las partes, la tradición o bien la entrega de la cosa que es su objeto. A él pertenecen el mutuo, el comodato y el depósito ${ }^{1}$. En ninguno de estos la convención meramente consensual, de todos modos necesaria, forma contrato obligacional, mientras no proceda una tradición en la donación y el mutuo, o una entrega en los demás mencionados; efectuada la cual y perfeccionado, por ende, el contrato, nace la obligación de restituir lo recibido (salvo en la donación, por cierto).

Consecuentes con esta postura, las definiciones que el Código peruano ofrece para cada uno de esos contratos tradicionalmente reales, aparece concebida en términos obligacionales, que merced al dispositivo del artículo 1352, antes transcrito, derivan de sólo el consenso, salvo la prenda y la anticresis, por las razones que diremos. Así, el artículo 1621 define que "Por la donación el donante se obliga a transferir gratuitamente al donatario la propiedad de un bien". El artículo 1648, a su vez, dice que "Por el mutuo, el mutuante se obliga a entregar al mutuario una determinada cantidad de dinero o de bienes consumibles, a cambio de que se devuelvan otros de la misma especie, calidad o cantidad". El artículo 1728, por su lado, expresa que "Por el comodato, el comodante se obliga a entregar gratuitamente al comodatario un bien no consumibles, para que lo use por cierto tiempo o para cierto fin y luego lo devuelva". Por el suyo, el artículo 1814 dicta que "Por el depósito voluntario el depositario se obliga a recibir un bien para custodiarlo $y$ devolverlo cuando lo solicite el depositante". En todos los casos, pues, el tipo consiste en que una de las partes "se obligue"; se entiende que en la donación y en el mutuo, la obligación es a transferir el donante el bien

${ }^{1}$ No era así en el Código de 1936, en que el mutuo, el comodato y el depósito eran reales: véanse las respectivas definiciones de los artículos 1537, 1587 y 1603 de ese Código, todas en el sentido de una perfección real de cada uno de esos contratos.

${ }^{2}$ En consecuencia, el artículo 1653 CCPer. declara que: "El mutuante está obligado a efectuar la entrega en la oportunidad convenida y, en su defecto, al momento de celebrarse el contrato".

${ }^{3}$ Por lo cual el artículo 1735 CCPer. establece como una de las obligaciones del comodante: "1. Entregar el bien en el plazo convenido". 
al donatario, o el mutuante la cantidad de consumibles al mutuario; en el comodato, es a entregar el comodante la cosa inconsumible al comodatario; y en el depósito, a recibir el depositario el bien y a entregarlo en devolución al depositante después.

En lo que concierne a la prenda y a la anticresis, el Código de 1984 no las considera contratos ni las expone, por ende, entre estos en el libro VII: Fuentes de las obligaciones, sección 2a: Contratos nominados; sino en el libro v: Derechos reales, sección 4a: Derechos reales de garantía, título $1^{\circ}$ : Prenda y título 2०: Anticresis. En todo caso, les conserva su tradicional carácter real. De la prenda, dice el artículo 1055, en efecto, que "se constituye sobre un bien mueble, mediante su entrega fisica o juridica, para asegurar el cumplimiento de cualquier obligación"; y de la anticresis añade el artículo 1091 "se entrega un inmueble en garantía de una deuda, concediendo al acreedor el derecho de explotarlo y percibir sus frutos". Así que, sea cual sea la naturaleza de ambos actos, no cabe duda ser la entrega la que los perfecciona. Por esta razón, advirtamos de inmediato que ellos han de quedar fuera de nuestro estudio.

Por lo que concierne a la donación, su carácter real u obligacional, derivado este último carácter de un consenso o de una forma convencional, desborda el preciso tema de la consensualización de los contratos reales, porque la duda y la discusión sobre uno u otro carácter de tal acto la ha cruzado a través de toda la historia del Derecho ${ }^{4}$, debido a lo cual también prescindiremos de ella aquí.

\section{LA PUESTA DEL CONTRATO REAL EN CRISIS}

1. Con la abolición de los contratos reales, el Código de 1984 adoptó cierta línea crítica formada en contra de ese tipo a fines del siglo XIX, que sólo la legislación suiza se atrevió a sancionar primero en 1883 y después en 1911, al conferir carácter consensual ${ }^{5}$ a los contratos de comodato ${ }^{6}$,

\footnotetext{
${ }^{4}$ Véanse Guzmán Brito, Alejandro, La estructura de la donación entre vivos y su emplazamiento sistemático en la jurisprudencia medieval y moderna y en la codificación", en Revista de Derecho de la Pontificia Universidad Católica de Valparaíso 25 (Valparaíso, 2004), pp. 199-267; y El mismo, De las donaciones. Conceptos y tipos (Santiago de Chile, LexisNexis, 2005), pp. 97-125.

${ }^{5} \mathrm{La}$ regla del consensualismo aparece en el artículo 1 de la Loi fédérale complétant le Code Civil suisse (Livre v: Droit des obligations), de 30 de marzo de 1911 (que es una revisión del Code Féderal des obligations de 1883): "1. Le contrat est parfait lorsque les parties ont, réciproquement et d'une manière concordante, manifesté leur volonté". La única excepción general aparece en el artículo artículo 11: "1 La validité des contrats n'est subordonnée à l'observation d'une forme particulière qu'en vertu d'une prescription spéciale de la loi". Entre ambas disposiciones no queda lugar para los contratos reales.

${ }^{6}$ Ibíd., artículo 305 (artículo 321 del código de 1883).
} 
mutuo $^{7}$ y depósito ${ }^{8}$. Cierto es que el Bürgerliches Gesetzbuch alemán de 1896 , entrado en vigencia en 1900 , había convertido en consensual al comodato\%; pero sólo a él, lo cual impide ver en tal postura una actitud antirealista de ese Código. En los decenios posteriores, códigos de segunda generación, como, notablemente, el italiano de 1942 y el portugués de 1966, entre los europeos; y el boliviano de 1975, el paraguayo de 1987, el quebequense de 1991 o el brasileńo de 2001, entre los americanos, no hubieron de atreverse a la conversión; y todos, pues, se mantuvieron atenidos fielmente a la tradición romanística en esta materia. Hizo excepción el Código cubano de 1987 que, en efecto, consensualizó los antiguos contratos reales de mutuo ${ }^{10}$, comodato $^{11}$ y depósito ${ }^{12}$, en orden a dejar obligados al mutuante y al comodante a entregar y al depositario a recibir. En cuanto a la prenda, le confirió naturaleza solemne, al exigir siempre un escrito ${ }^{13}$, y no queda claro de la sola lectura de ese cuerpo legal si la entrega es necesaria, además, para la perfección del negocio, o sólo el objeto de una obligación derivada de la solemnidad que previamente perfeccionaría el contrato ${ }^{14}$. En lo concerniente a la donación, tampoco es clara su naturaleza real o consensual ${ }^{15}$. En Europa, el nuevo Código Civil de Holanda (Burgerlijk Wetboek), de 1992, confiere carácter consensual al depósito ${ }^{16}$. Más recientemente, la "Ley de modernización del Derecho de obligaciones" (Gesetz zur Modernisierung des Schuldrechts), de 26 de noviembre de 2001, entrada en vigencia el 1 de enero de 2002, que principalmente modificó el libro II del BGB., extendió el carácter consensual al mutuo ${ }^{17}$, pero conservó

${ }^{7}$ Ibíd., artículo 312 (artículo 329 del código de 1883).

${ }^{8}$ Ibíd., artículo 472 (artículo 475 del código de 1883).

${ }^{9}$ BGB., $\$$ 598: "Durch den Leihvertrag wird der Verleiher einer Sache verpflichtet, dem Entleiher den Gebrauche der Sache unentgeltlich zu gestatten" "Por el comodato, el comodante de una cosa es obligado a conceder el uso gratuito de la cosa al comodatario").

${ }^{10}$ CCCub., artículo 379.

${ }^{11}$ CCCub., artículo 382.

${ }^{12}$ CCCub., artículo 423.

${ }^{13}$ CCCub., artículo 270 No 4.

${ }^{14} \mathrm{El}$ artículo 270 No 12 solo habla de un "bien mueble recibido del deudor".

${ }^{15} \mathrm{El}$ artículo 371 define al acto en términos de un contrato que "transmite la propiedad", lo que indica el carácter real; pero el artículo 372 habla de una promesa de donación, que obliga al ser aceptada.

${ }^{16}$ CCHol., libro VII, artículo 600, según el cual, el depositario se obliga a guardar y a devolver una cosa que le confía o le confiará el depositante. Del mutuo y del comodato se habrá de tratar en la continuación del libro VII, que está pendiente aún. Seguramente también esos contratos han de aparecer consensualizados.

${ }^{17}$ BGB. (nuevo) $\$ 607$. 
el real al depósito ${ }^{18}$. La reforma, por otro lado, no afectó al Derecho de bienes ("Sachenrecht"), por lo cual la prenda, que a aquél se ve totalmente atraída en el BGB., no varió su anterior estatuto de acto real ${ }^{19}$.

2. Al menos en 1906, el conocido jurista francés Gabriel Baudry-Lacantinerie (1837-1913) verificaba que la atribución del carácter real por el Code Civil a los contratos de mutuo, comodato, prenda ${ }^{20}$ y depósito era una "théorie qui a pour elle presque l'unanimité de la doctrine"21. La limitación señalada con "presque" provenía de un autor que Baudry-Lacantinerie identifica como M. Vigié, según el cual, en el Derecho francés, todos los contratos, sin excepción, se forman por el simple consentimiento, de modo que la entrega de la cosa no es una condición de la formación de los antes mencionados contratos, sino la ejecución de una obligación previamente nacida de ellos ${ }^{22}$. Acto seguido, Baudry-Lacantinerie criticaba esta opinión, en cuanto aparecía como una interpretación del Derecho francés vigente, por tener en su contra a los textos y a la tradición ${ }^{23}$. Lo cual no significa que, "en pure théorie" -añadía-, la solución del Code Civil, en orden a exigir la entrega de la cosa para perfeccionar los contratos de mutuo, comodato, prenda y depósito, no mereciera críticas. Baudry-Lacantinerie explica que la obligación de devolver, propia de esos contratos, no es incompatible con su consideración como consensuales, tal cual acaece en el arrendamiento de cosas; y que, como, en el Derecho francés, los contratos de promesa de dar en mutuo, entregar en comodato, de recibir en depósito y de entregar en prenda son válidos, entonces "pourquoi décider que la rémise ultérieure de la chose aura pour effet de former un nouveau contrat, un contrat réel? Cette complication est inutile". $\mathrm{Al}$ autor, pues, le parecía correcta la refundición de la promesa de contrato real y el contrato real prometido mismo en uno sólo, que tendría carácter consensual. En apoyo, terminaba citando el ejemplo del Code federal des obligations suizo (de 1883), que, como antes hicimos notar, ya acordaba naturaleza consensual al comodato, al mutuo y al depósito ${ }^{24}$.

3. Como vimos, al menos hacia 1906, este autor consideraba "casi

${ }^{18}$ BGB. $\$ 688$.

${ }^{19}$ BGB. $\$ 1.295$, el cual exige la entrega de la cosa pignorada.

${ }^{20}$ Como se sabe, en el Derecho francés, la prenda es un contrato real.

${ }^{21}$ Baudry-Lacantinerie, Gabriel, Traité théorique et pratique de Droit civil des obligations (3a edición, Paris, 1906), I, núm. 23, p. 23. Dije "al menos en 1906", debido a que sólo he podido examinar, como se ve, la tercera edición de este libro; así que es probable que el autor ya hubiera hecho la afirmación transcrita en la primera.

${ }^{22}$ Ibíd., pp. 24-25.

${ }^{23}$ Ibíd., pp. 25-30.

${ }^{24}$ Ibíd., pp. 30-31. 
unánime" (en Francia) la doctrina sobre la naturaleza real de los contratos de comodato, mutuo, depósito y prenda en el orden de lege data. En el de lege ferenda, aparenta haber sido él el primero en aconsejar la conversión de tales contratos en consensuales. Esta última opinión ha ganado paulatino terreno.

En 1962, Gabriel Marty y Pierre Raynaud, en efecto, escribían: "Mais cette notion de contrat réel est de plus en plus contestée. [...] aujourd'hui que le simple consentement suffit à obliger, cette remise est inutile et les partisans de la notion de contrat réel sont obligés de reconnaître que, dès avant la remise de la chose, certaines obligations peuvent naitre par le seul accord de volontés et d'admettre la valeur d'une promesse consensuelle de contrat réel. Ainsi si une personne promet de prêter à une autre qui accepte de payer un intérêt, il y a engagement valable des deux parties, bien qu'il n'y ait pas eu encore remise des deniers et il est bien inutile de scinder ainsi en deux contrats distincts et successifs une opération qui forme un tout./ Les prétendus contrats réels ne sont que des contrats consensuels [...]"25. En nota citan a diversos juristas impugnadores de la noción de contrato real $^{26}$. Más modernamente, se pronuncian en el mismo sentido juristas aun vivientes como Christian Larroumet ${ }^{27}$ o François Chabas ${ }^{28}$.

4. La postura antirealista, sin embargo, no se expone sin contradictores. Aquí recordaremos algunas opiniones importantes.

En 1948 se trató de derogar el principio realista en el seno de la Commission de Réforme du Code Civil, a la sazón presidida por Léon Julliot de la Morandière ${ }^{29}$. El autor de la proposición fue Henri Mazeaud, secundado por otros colegas. En la discusión quedaron planteados los argumentos entre los cuales por reglas general se ha movido la doctrina francesa posterior: en pro del contrato real, que no puede haber obligación de restituir sin previa tradición o entrega; y en contra, que es una complicación inútil distinguir un contrato (consensual) de promesa de contrato real, que obliga

${ }^{25}$ Marty, Gabriel - Raynaud, Pierre, Droit civil (Paris, Sirey, 1962), II, 1: Les obligations, núm. 60, p. 48.

${ }^{26}$ Ibíd., p. 48 n. 1, entre los más conocidos: Colin, Capitant y Julliot de la Morandière (Traité de Droit civil), Ripert y Boulanger (Traité de Droit civil), Planiol y Ripert (Traité pratique), Esmein (6a edición del viejo tratado de Aubry et Rau), Demogue (Obligations).

${ }^{27}$ Larroumet, Christian, Droit civil (3a edición, Paris, Economica, 1996), núm. 522, pp. 504-505.

${ }^{28}$ Chabas, François, Obligations: théorie genérale, en Mazeaud, Henri y Léon - Mazaud, Jean - Chabas, François, Leçons de Droit civil (9a edición, Paris, Montchrestien, 1997), II, 1, núm. 82, p. 71 [hay una 12a edición, de 2000].

${ }^{29}$ Travaux de la Commission de Réforme du Code Civil. Année 1947-1948 (Paris, Sirey, 1949), sesión de 18 de junio de 1948, pp. 279-283. 
a entregar, y un contrato real posterior que se perfecciona por la entrega. El presidente Julliot de la Morandière añadió un elemento cultural: "Les codes modernes qui ignorent le contrat réel ont été rédigés à une époque où le consensualisme, l'individualisme, la volonté de l'individu étaient considères comme la source unique du contrat. Mais la vraie source, dans certains contrat, est la remise de la chose" ${ }^{30}$. Citamos con sus palabras originales esta opinión, porque en nuestro tiempo Jean Carbonnier la ha rescatado en apoyo a sus dudas acerca de la tendencia antirealista: "une voix éminente -recalca- a fait remarquer quel'hostilité à la théorie des contrats réels datait d'une époque où, à travers le consensualisme, l'individualisme était roi" 31 . Carbonnier también apoya sus dudas en un dato sociológico: "Nosotros tenemos todavía contratos reales y se puede poner justamente en duda si, en nuestro análisis civilista del contrato, hemos hecho suficiente sitio a esta categoría de los contratos formados re, acosados como un arcaísmo en nombre de la autonomía de la voluntad, pero quizá más viva de lo que pensamos, porque responde a un dato primitivo del derecho contractual" 32 .

Mas recientemente, Jacques Ghestin ha retomado y desarrollado las razones de Carbonnier. Después de resumir los argumentos tradicionales de la doctrina antirealista: ser el contrato real un arcaísmo y significar una innecesaria complicación del sistema general consensualista, al exigir dos contratos, una promesa y el acto real posterior, si se quiere hacer obligatoria la entrega, añade: "Il est permis de penser cependant que l'hostilité à la théorie des contrats réels appartient elle-même au passé, et plus précisément qu' elle date 'd'une époque où, à travers le consensualisme, l'individualisme était roi' ${ }^{33}$. 'On peut mettre en doute que, dans note analyse civiliste du contrat $[. . .]^{34}$. En fait, la catégorie des contrats réels traduit l'importance du déplacement de valeur et exprime une conception moins intellectuelle, plus concrète, et par là plus vraie, des relations contractuelles"35. Ghestin, pues, a partir de las ideas de Carbonnier, quiere llamar la atención acerca

${ }^{30}$ Ibíd., p. 282.

${ }^{31}$ Carbonnier, Jean, Droit civil, IV: Les obligations (6a edición, Paris, Presses Universitaires de France, 1969 [hay una 22a edición, de 2000]), núm. 43, p. 140.

${ }^{32}$ Carbonnier, Jean, Derecho flexible. Para una sociología no rigurosa del Derecho (traducción de L. Díez-Picazo, Madrid, Tecnos, 1974), pp. 252-253.

${ }^{33} \mathrm{La}$ cita es a Carbonnier, véase la nota 31 [pero se observará que la cita de Ghestin es erróneamente a un núm. 93 por 43].

${ }^{34}$ Se trata de otra cita a Carbonnier, véase la nota 32.

${ }^{35}$ Ghestin, Jacques, La formation du contrat, en Traité de Droit civil sous la direction de Jacques Ghestin (3a edición, Paris, Librairie Générale de Jurisprudence, 1999), núm. 452, p. 419. 
del hecho de que en los actos y contratos la voluntad no lo es todo, y que, pensar lo contrario, es situarse en un pasado (no remoto), en que se creyó ser suficiente aquella para explicar cualquier extremo del contrato. Alegar el ejemplo de aquellos contratos consensuales en que hay también entrega, como el arrendamiento o el transporte de mercaderías, eso "montre simplemente que, dans ces contrats aussi, des eléments matériels coexistent avec le rôle de la volonté" ${ }^{36}$. Lo cual también ocurre -añade- en la compraventa misma (el prototipo de contrato consensual en que la entrega no cumple ninguna función generadora de obligaciones), como lo muestra la práctica corriente de darse arras las partes, lo cual traduce "cette conception plus concrète des relations contractuelles" ${ }^{37}$. Continúa con el argumento maestro de la defensa del realismo: sin entrega no puede haber obligación de restituir, frente a lo cual "la volonté des parties est impuissante à écarter ce qui résulte de la nature des choses" ${ }^{38}$. Termina declarando no ver dificultades en aceptar la noción de contrato real una vez adoptada la de promesa de contrato real, para dejar a la opción de las partes escoger entre obligarse inicialmente una de ellas a entregar, mediante una promesa; o no obligarse y formar el contrato sólo desde el momento de la entrega.

En general, quienes toman partido por conservar la categoría de los contratos reales hacen ver que los inconvenientes prácticos que ellos pueden ofrecer a veces, se solucionan merced al instrumento de la promesa de contrato real. Tal es, por lo demás, el núcleo de un extenso trabajo de Jobard-Bachellier, publicado en $1985^{39}$, en que demuestra punto por punto la validez de tal promesa, salvo escasas excepciones, de tal modo que concluye, por lo que al problema de fondo atañe: "Ces solutions, qui réservent encore une place à la remise comme condition de formation des contrats dans certaines des conventions considérées traditionnellement comme réelles, constituent-elles une anomalie difficilement acceptable dans un système, comme le système juridique français, qui serait entièrement consensualiste? Nous ne le croyons pas; ces solutions sont le résultat non fortuit d'exigences bien réelles issues d'un équilibre fondamental à respecter entre la force de la volonté, la force du consentement donné, d'une part, et la force de ce fait matériel, représenté par la déplacement d'un bien corporel d'un patrimoine à un autre, qui seul peut avoir pour effet de mettre la chose concrètement et définitivement, à la disposition

${ }^{36}$ Ibíd.

${ }^{37}$ Ibíd.

${ }^{38}$ Ibíd.

${ }^{39}$ JoBARD-BACHELliER, Marie-Noëlle, Existe-t-il encore des contrats réels en droit français? ou la valeur des promesses de contrat réel en droit positif, en Revue Trimestrelle de Droit Civil 84 (janvier-mars 1985) 1, pp. 1-62. 
d'autrui $[\ldots]^{\prime 40}$.

En suma, no puede decirse ser predominante en el día la tesis antirealista, que, por lo demás, nunca ha contado con el favor de la jurisprudencia: "L'attachement de la jurisprudence à la notion de contrat réel a, au demeurant, conduit -dicen tres juristas del día- un courant doctrinal important à prendre conscience de ce que celle-ci n'était peut-être pas aussi archaïque qu'on l'a prétendu" 41 .

\section{LA ESTRUCTURA DEL CONTRATO REAL}

Propondremos en este trabajo un examen de las exigencias dogmáticas contenidas en la conversión de los contratos reales en consensuales, y de sus supuestos y efectos prácticos, en función de verificar la regularidad jurídica de tal conversión.

Preliminarmente, debemos examinar la estructura de los contratos reales de que aquí tratamos, a saber, del mutuo, el comodato y el depósito.

1. En todos ellos observamos una estructura ciertamente unitaria, pero de dos niveles.

a) El primero corresponde a la necesaria convención entre dos partes, que lógica aunque no siempre cronológicamente debe preceder al perfeccionamiento del contrato. En ellas queda definido el contenido típico del contrato por celebrar; y se trata, en consecuencia, de un acuerdo de dar y recibir cierta cantidad de fungibles en préstamo; de entregar y recibir gratuitamente una especie no fungible en uso; de entregar y recibir una especie no fungible en custodia. La convención identifica al futuro contrato en su esencia, y delimita que se trata, respectivamente, de un mutuo, o de un comodato, o de un depósito..

Esta convención es enteramente consensual; pero no produce efecto obligacional alguno; vale decir, sus partes no quedan obligadas a dar, en el caso del futuro mutuante y recibir, en el del futuro mutuario; o a entregar y a recibir, en los demás casos. Cada una puede arrepentirse, pues, sin que la contraparte que iría a recibir disponga de una acción dirigida a conseguir el cumplimiento forzado de la dación, en su caso, o de la entrega; ni que aquella que iría a dar o entregar disponga de otra acción encaminada a forzar la recepción de la cosa por la otra; o a obtener, en ambos casos, la indemnización del daño emergente y el lucro cesante.

Problema distinto es si, en el caso de incumplimiento del anuncio de dar o entregar, o del de recibir, puede el interesado intentar conseguir la

${ }^{40}$ Ibíd., p. 62.

${ }^{41}$ Terré, François, - Simler, Philippe - Lequette, Yves, Droit civil. Les obligations (9ª edición, Paris, Dalloz, 2005), núm. 49, p. 161. 
indemnización extracontractual del daño patrimonial causado por tal incumplimiento, considerado como hecho doloso o culposo que causa perjuicio a otro.

b) El segundo plano corresponde a la tradición de la cosa en el mutuo, o a la mera entrega en los demás casos. Si el anterior era un plano puramente consensual, este es un plano real, llamado así por el movimiento efectivo de una cosa, consistente en su traspaso de una parte a otra mediante la entrega, que es propiamente tradición, como se sabe, en el mutuo, y mera entrega en el comodato y el depósito.

2. Ahora bien, en el momento en que la tradición o la entrega quedan consumadas, se perfecciona el respectivo contrato. Entonces, la precedente convención consensual empieza a tener efecto, consistente en funcionalizar la tradición como mutuaria, o la entrega como comodataria o depositaria; y decimos que constituye la causa o el título de una u otra: pasa a ser la causa credendi en el mutuo, y constituye, pues, el título traslaticio de dominio de su tradición; o pasa a ser el título no traslaticio de dominio o título de mera tenencia en los demás casos. Esta función es sumamente importante, debido a que la tradición y la entrega, en sí mismas, son actos neutros, carentes de contenido propio, que no sea el de precisamente traspasar una cosa, y de un propio efecto jurídico pre-tipificado; en tales circunstancias, el efecto que hayan de producir les viene de su causa o título. Si la entrega de un bien es en mutuo, comodato o depósito, eso solo se puede saber al examinar la causa de esa entrega, constituida por la convención consensual que antes estudiamos.

El complejo integrado por la convención consensual y la entrega es el que llamamos contrato real; cuyo efecto, a su vez, es servir de causa o fuente a una obligación de carácter restitutorio: el que recibió resulta, en efecto, obligado a restituir, otras especies, pero del mismo tanto, género y calidad que las recibidas, en el caso del mutuo; o la misma especie, en el del comodato y del depósito..

Esta es la estructura esencial de los contratos reales cuya propuesta abolición debemos examinar.

\section{LA ESTRUCTURA SINALAGMÁTICA O BILATERAL DE LOS CONTRATOS CONSENSUALES SUSTITUTIVOS DE LOS REALES}

La sustitución de los contratos reales por sendos contratos consensuales implica operar una doble conversión en el sistema: i) por un lado, la conversión de la causa, radicante en la convención consensual definidora de la futura operación, en contrato consensual (o solemne, si es que se quiere, lo que debemos dejar a un lado en el análisis); y b) por otro, la conversión 
de la entrega causada y perfeccionadora del contrato real en cumplimiento del contrato consensual. Así por lo menos debería ser.

Esto se podría intentar hacer de dos maneras:

a) La primera es crear un contrato consensual obligacionalmente sinalagmático o bilateral. Si consideramos el caso del mutuo, aquello consistiría en un consenso en orden a obligarse a dar en préstamo una cantidad de fungibles, por una parte, y a recibirla por la otra. El mutuante, pues, quedaría obligado a dar y el mutuario a hacer, consistente en recibir; y cada uno dispondría de una acción personal al efecto. Consecuentemente, se deberían aplicar a estas obligaciones las reglas generales sobre cumplimiento, mora, ejecución forzada en especie o por equivalencia, indemnización de perjuicios por daño emergente y lucro cesante, etcétera. Cuando se mira a los demás contratos reales, la primera obligación, la del comodante y del depositante, sería, no de dar, por cierto, sino de entregar. En el resto es aplicable lo dicho para el mutuo.

b) La segunda manera es crear un contrato consensual obligacionalmente unilateral, en que la parte activa quedaría obligada a dar, en el caso del mutuo, o a entregar, en el del comodato, pero no a recibir la parte pasiva, salvo en el depósito, quien, en consecuencia, podría desistirse del contrato hasta el instante previo a la recepción. Sólo, pues, la parte pasiva dispondría de una acción personal para forzar la tradición o la entrega, según el caso, de la activa; pero no ésta para forzar la recepción de la cosa por la contraparte, salvo en el depósito.

A mi juicio, tales son las opciones que tiene abiertas el legislador que haya decidido extinguir el tipo real de contratos.

\section{LA OBLIGACIÓN DE RESTITUIR}

1. En Francia, François Chabas ha planteado que los contratos consensuales sucesores de los reales podrían ser sinalagmáticos o bilaterales, pero en otro sentido. Según él: "Lensemble de l'operation juridique s'analyserait alors en un contrat consensuel synallagmatique, c'est-à-dire faisant naître deux obligations reciproques: le prêteur s'engage à remettre la chose, el l'emprunteur s'oblige à la restituer si elle lui est remise"42. En el mutuo y el comodato, la sinalagmaticidad estaría constituida por el entrecruce de la obligación de la parte activa consistente en dar o entregar, según el caso, y de aquella de la parte pasiva consistente en restituir. En ninguno de estos contratos caso habría obligación de recibir. Chabas nada dice de especial en torno al depósito gratuito, pero podemos suponer que él sería

${ }^{42}$ Chabas, François, Obligations, cit. (n. 28), núm. 82, p. 71 
siempre unilateral, aunque de doble unilateralidad, pues solo el depositario se obligaría, y se obligaría tanto a recibir como a restituir, mientras que el depositante no quedaría obligado a entregar, como es natural. Si el contrato es oneroso, en cambio, este último contraería la obligación de pagar la remuneración acordada y sería, por ende, bilateral.

Chabas entiende que la obligación de restituir emana, pues, del consenso contractual, aunque -añade- bajo la condición de haber habido entrega: "l'emprunteur s'oblige à la restituer si elle lui est remise". Previamente había declarado: "on peut s'engager à restituer une chose quand elle sera remise: obligation sous condition suspensive de la remise" 43

Esta construcción es necesaria porque va de suyo que en el mutuo, el comodato y el depósito tiene que existir una obligación restitutoria de lo recibido; de lo contrario todos ellos se convertirían en donaciones. En esos contratos concebidos como reales, la causa o fuente de tal obligación es la tradición o entrega, según el caso. Ahora bien, al concebírselo como consensuales, se quiere ver la causa o fuente de la obligación restitutoria en el consentimiento contractual mismo. Pero ese consentimiento tiene lugar antes de la entrega, en circunstancias de que para existir una obligación de restituir, previamente tuvo que haber habido una recepción, la cual supone, a su vez, una entrega. Nadie puede obligarse a devolver lo que nunca le fue entregado ni recibió. Así que es imposible que la parte pasiva del contrato consensual de mutuo, por ejemplo, quede obligada a devolver la cantidad de fungibles a que el contrato se refiere, si éste ya no consiste en darla el mutuante al mutuario y en recibirla éste, sino en obligarse a dársela el primero, porque se obligaría a restituir antes de haber recibido. Lo propio cabe decir con respecto a los demás contratos ahora reales, una vez convertidos en consensuales. La única manera de encajar satisfactoriamente una obligación pertinente a la restitución en cabeza de la parte pasiva, es -como bien lo ve Chabas- bajo condición.

2. Cumple, por consiguiente, analizar el perfil dogmático de esta condición. La cual tendría que ser configurada como el hecho futuro e incierto de entregarse y recibirse la cosa de que se tratare; y sería, por ende, positiva y suspensiva. Pendiente tal condición, la obligación de restituir no existe; y deja definitivamente de poder empezar a existir si falla, vale decir, si la cosa no es entregada o recibida; pero empieza a existir al cumplirse la condición, consistente en el hecho de la entrega y de la recepción; existencia aquella que se retrotrae o no al momento de haberse perfeccionado el contrato, que es el del consentimiento, según que el sistema acepte o

${ }^{43}$ Ibíd. 
no la retroacción ${ }^{44}$.

Se observará que la condición de que hablamos consiste en que la cosa sea entregada y recibida; no basta, pues, la entrega si no siguió una recepción, no bien que cuando no haya existido esta última, en realidad no pueda hablarse propiamente de entrega, sino de oferta de entrega. Por consiguiente, en la hipótesis de ausencia de recepción, por cualquier causa, y en especial en la de repudio de la oferta, la condición falla y la obligación de restituir no nace. Esto debe ser entendido así, porque por más que la parte activa esté dispuesta a entregar, si la pasiva no recibe, no puede resultar obligada a restituir. En el caso contrario, se formaría una hipótesis de lo que suele ser llamado enriquecimiento sin causa, pues la parte activa podría exigir algo que tiene y nunca dejó de tener, y la pasiva ser obligada a devolver algo que no tiene y nunca empezó a tener.

Para ilustrar la idea de que la obligación de restituir puede ser atribuida al consenso contractual, suele recurrirse al ejemplo del arrendamiento, en que el arrendatario se obliga a restituir, pese a que la entrega no perfecciona al contrato, que es consensual, y a que puede ella advenir tiempo después de celebrado ${ }^{45}$.

\section{EL EMPALME DE LA OBLIGACIÓN DE RESTITUIR EN LOS CONTRATOS CONSENSUALES SUSTITUTIVOS}

Con todo, esta construcción ofrece dificultades dogmáticas de relieve.

1. Hemos concluido, con Chabas, que la obligación de restituir la cosa, que pesa sobre la parte pasiva del contrato, debe ser construida como una obligación sometida a condición positiva suspensiva de que esa cosa sea entregada y recibida. Ahora bien, el análisis de tal condición muestra su carácter complejo, pues ella envuelve cuatro acaecimientos: i) el hecho voluntario de ofrecer entregar la cosa el acreedor; y ii) su alternativa, de no querer entregarla; iii) el hecho voluntario de recibir la cosa el deudor; y iv) su alternativa de no querer recibirla. Dos de estos supuestos dependen de la voluntad del acreedor y dos de aquella deudor; pero ninguno de terceros ni del acaso. En consecuencia, la condición, mirada unitariamente ahora, es potestativa, y no casual ni mixta. Descompuesta ella de nuevo en los cuatro supuestos enunciados, resulta ahora que tres no ofrecen reproche alguno, pues i) ofrecer entregar el acreedor es un hecho voluntario suyo, de modo que, convertido en condición, pertenece a las llamadas simplemente potestativas, que valen; ii) no querer entregar el mismo acreedor,

\footnotetext{
${ }^{44}$ No la acepta el CCPer., artículo 177 , salvo pacto en contrario.

${ }^{45}$ Así, ya Baudry-Lacantinerie, Gabriel, Traité, cit. (n. 21),
} 
aunque ya no es un hecho voluntario, mas solo una declaración, expresa o tácita de voluntad, una vez convertida en condición, vale, tanto como valen las condiciones meramente potestativas del acreedor; iii) recibir el deudor también es un hecho voluntario suyo, que, convertido en condición, se hace perteneciente al tipo de las simplemente potestativas del deudor, que valen; pero iv) no querer recibir ese deudor, como tampoco es un hecho voluntario suyo, sino únicamente una declaración, expresa o tácita, de voluntad, al ser deducido en condición hace nulo al acto, porque el artículo 172 CCPer. precisamente declara tal a aquellos cuyos efectos están subordinados a una condición suspensiva que consiste en la exclusiva voluntad del deudor. Y, en efecto, le basta al deudor no querer recibir para que la condición falle. Este elemento meramente potestativo contamina a toda la condición, de nuevo considerada unitariamente, y ella, a su vez, al acto, porque resulta ser claro que el efecto de éste, vale decir, la obligación, en final de cuentas depende de la mera voluntad del deudor; y es como si el deudor hubiera declarado: "me obligo a restituir si quiero obligarme a restituir". Ello equivale a una ausencia de consentimiento, que es la razón dogmática por la cual se anulan los actos sometidos a condiciones meramente potestativas del deudor. En tales circunstancias, la obligación de restituir no es que pueda no llegar a nacer, sino que no puede llegar a nacer, atendida la nulidad del acto de que emana

2. A esta dificultad dogmática se añade en los ordenamientos que aceptan la retroacción de las condiciones cumplidas -que no es el caso del Código peruano- una segunda, que admite ser formulada así: cuando se da por cumplida la condición, porque hubo entrega y recepción de la cosa, tal cumplimiento actúa retroactivamente, en el sentido de deber considerarse a la obligación como nacida pura y simplemente en el momento de perfeccionado el contrato sin jamás haber estado pendiente. De ello se sigue que la obligación de restituir, que no puede nacer, como se vio, antes de la entrega, nació, sin embargo, cuando la cosa aun no había sido entregada; lo cual constituye un contrasentido imposible de aceptar, aunque haya sido provocado por una ficción.

La única manera de evitar este desaguisado lógico es declarar que en la materia el efecto retroactivo no opera, y que la obligación de restituir nace con la entrega y la recepción únicamente para el futuro, no para el pasado, de modo que en el tiempo intermedio no existió. Tal tiene que ser la construcción en el Derecho peruano. Pero ello implica negar que la obligación restitutoria queda conectada con el consentimiento contractual, y que éste sea su fuente; y lleva a la conclusión de que en la operación hay, en realidad, dos contratos: el consensual y el real, pues si la entrega y no el consenso genera la obligación de restituir, y la entrega es un acto 
convencional, no queda otra opción que darle el carácter de contrato.

3. Se ve, pues, que obligación condicional de restituir no puede ser correctamente incrustada en la estructura de los contratos consensuales sustitutivos de los que son reales. Y es completamente normal que ocurra así, porque ya la idea básica, de que la obligación de restituir depende del consenso contractual, es errada, al ser imposible que una obligación de restituir, que solo puede existir después de recibir, quede imputada a un consenso primordial otorgado antes de entregar. De esta falsa premisa no pueden sino que seguirse incongruencias dogmáticas, que no se arreglan con la segunda idea de la entrega como condición, porque ella conduce a nuevas incongruencia, que nos porta a una telarańa de sutilezas dialécticas. Pero no nos engañemos, pues tales sutilezas son consecuencia directa de la sutileza inicial de suponer que un puro consenso es capaz de generar la obligación de restituir.

4. No es el caso del contrato de arrendamiento de cosas. Consiste éste en un consentimiento recíproco que obliga al arrendador a ceder temporalmente el uso de un bien al arrendatario, y a éste, a pagar cierta renta convenida (artículo 1666 CCPer.). No consiste en un consentimiento que obliga al arrendador a entregar una cosa y al arrendatario a restituirla. Ahora bien, el arrendador debe hacer varias cosas para cumplir su obligación de ceder el uso de la cosa arrendada al locatario: debe empezar por entregársela (artículo 1678 CCPer.); continuar con la conservación de la cosa en estado de servir para el fin por el que se la arrendó (artículo 1680 No 1 CCPer.), reparándola cuando sea preciso (artículo 1680 No 2 CCPer.); y finalizar por la mantención del arrendatario en el uso de bien, lo cual implica la evitación de toda turbación o embarazo en tal uso (artículo 1680 No 1 CCPer.). El arrendatario, por su parte, debe, en síntesis, usar correctamente la cosa, repararla cuando ello sea de su cargo y pagar la renta convenida (artículo 1681 CCPer.).

En cuanto a la restitución, aunque el Código diga ser obligación suya (artículo 1681 No 10 CCPer.), y en términos amplios pueda aceptarse que es así, estrictamente hablando es una natural secuela de la terminación del contrato, a la que debe proceder el arrendatario (artículo 1704 CCPer.). Así que la restitución no es una obligación principal del arrendamiento, y no alcanza hasta permitir calificarlo como un contrato de restitución. En efecto, es innecesario y superfluo que el arrendatario se obligue a restituir, porque ello necesariamente acaecerá por haber recibido la cosa y haber terminado el contrato. Lo único que no puede hacerse es excluir la restitución, que convertiría al arrendamiento en otro contrato.

5. Todavía podemos examinar la hipótesis de un contrato desarrollado en el uso bancario, al que suele designarse como "contrato de línea de cré- 
dito", y que se originó en la antigua práctica de los sobregiros autorizados unilateralmente por el banco o previa petición del cuentacorrentista. Por él, un banco se obliga a pagar los cheques girados por un cuentacorrentista sin el respaldo de fondos en su cuenta, hasta cierto monto total acordado. El cuentacorrentista debe restituir las cantidades sobregiradas y sus intereses, en determinadas condiciones de tiempo. La obligación de restituir y de pagar intereses no nace, por cierto, sino con el pago del cheque sobregirado. Pero el contrato es legalmente consensual (si bien, en la práctica, los bancos lo formalizan merced a la exigida firma de varios instrumentos privados apropiados), y no real; así que, con su celebración, el banco queda obligado a cubrir los cheques sobregirados, y debe responder del perjuicio causado por la omisión injustificada de cobertura y del eventual protesto por falta de fondos. En el fondo, lo que el banco debe hacer es atender a la petición de crédito por parte del cliente, petición que se manifiesta con la presentación del cheque sobregirado por su beneficiario (que por supuesto puede ser el mismo cuentacorrentista) en caja, o por otro banco en el momento de la compensación bancaria, si el cheque fue depositado en él. El cliente se asegura, de esta manera, tener crédito abierto para cuando lo necesite.

Igual que en el arrendamiento, la obligación de restituir no nace del consenso contractual sino del acto real, consistente en el pago que el banco hace del cheque presentado a caja o a compensación. El cuentacorrentista no necesita obligarse consensualmente a la restitución, porque igual quedará obligado merced al acto real, que no tiene carácter donatorio ni solutorio de algún crédito del cuentacorrentista. Tanto es así, que incluso cuando no mediara el contrato de línea de crédito y el banco decidiera pagar el cheque llegado a él en descubierto, aun así el cuentacorrentista quedaría obligado en fuerza del acto real.

6. Es posible, pues, generalizar. Que la parte pasiva se obligue consensualmente a restituir es superfluo, pues igualmente resulta obligada a ello en fuerza de la entrega y recepción, desde que este acto real no tiene significado donatorio ni solutorio, que le permitiría retener definitivamente. De hecho, en los contratos reales el punto relativo a la restitución no es nunca objeto de convención, que solo se refiere a las modalidades de aquélla, como el plazo o el fin y otras circunstancias. Es suficiente que no se declare que el receptor no habrá de restituir, porque si tal se hiciese, ello implicaría que no se trata de un mutuo, un comodato o un depósito. Pero no se requiere por innecesario declarar que el receptor sí queda obligado a restituir.

7. En tales circunstancias, los contratos consensuales sustitutivos de los reales deben limitarse a prever la obligación de dar o entregar para una parte y la de recibir para la otra, excepto el depósito, si se los construye como 
sinalagmáticos; o solo la primera, y la de recibir en el depósito, cuando se los conciba como unilaterales.

La obligación de restituir, que no puede nacer del contrato consensual, solo nace de la entrega y recepción de la cosa, consideradas no como condición. Pero de que una y otra constituyan el cumplimiento de aquel contrato, que determinan la extinción de sus obligaciones, se sigue que la entrega y la recepción son, al mismo tiempo, la fuente de una obligación nueva, que antes no existía. Y como, a su vez, la entrega y la recepción constituyen un acto convencional, he ahí que en definitiva constituyen un contrato, el cual es necesariamente real, porque existe y es perfecto en cuanto haya habido entrega y recepción.

La conclusión final es que la creación de los contratos consensuales no suprime a los contratos reales; sólo los posterga; y que, quiérase o no, ellos consiguen introducirse en el sistema, negándose a morir; si se prefiere, son inmortales. Así que el argumento que suele esgrimirse ${ }^{46}$, en orden a que la creación de los contratos consensuales permite economizar en la actuación jurídica, que en otro caso se complica por el desdoblamiento en la celebración, primero de una promesa de contrato real, y luego del contrato real mismo, es falso. No se economiza nada, pues igual hay dos contratos que celebrar, uno consensual y otro real. En final de cuentas, los contratos consensuales sustitutivos de los reales vienen a equivaler a las promesas de estos últimos. En efecto, si alguien promete celebrar un mutuo, esto es, dar credendi causa una cantidad de fungibles, y no cumple, la condena es a celebrar el contrato, vale decir, a dar la cantidad, lo mismo que si hubiera celebrado un contrato consensual de mutuo, que lo dejó obligado a dar la cantidad ${ }^{47}$.

${ }^{46}$ Es común en la doctrina francesa antirealista, desde BAUDRY-LACANTINERIE, Gabriel, Traité, cit. (n. 21), núm. 23, p. 30: "cette complication est inutile"; Mazeaud, Heni, en Travaux, cit. (n. 29), p. 280: "Ce sont des complications intiles"; Marty, Gabriel - Raynaud, Pierre, Droit civil, cit. (n. 25), 60, p. 48: “[...] il est bien inutile de scinder ainsi en deux contrats distincts et successifs une opération qui forme un tout"; Larroumet, Christian, Droit civil (cit. 27), núm. 522, p. 505: "cette notion qui est inutile".

${ }^{47}$ Un entusiasta crítico de la noción de contrato real, como Larroumet, Christian, Droit civil (cit. 27), núm. 522, p. 504, se ve implícitamente obligado a reconocer este similar efecto, aunque rehuye la conclusión. Parte diciendo que una promesa de contrato real no es lo mismo que el contrato real, porque la jurisprudencia francesa tiene decidido que, en caso de incumplimiento de la promesa de mutuo, la condena es a la indemnización de perjuicios, y no a la ejecución del contrato prometido. Enseguida considera que tal solución es errónea, y que lo procedente es condenar a la ejecución, lo cual implica dar la cantidad a que se refería el mutuo. Pero, en vez de concluir que entonces da lo mismo la promesa de mutuo que el contrato consensual de mutuo, 


\section{EL EMPALME DOGMÁTICO DE LA OBLIGACIÓN DE RECIBIR EN LOS CONTRATOS CONSENSUALES SINALAGMÁTICOS}

Volvamos a los contratos consensuales construidos como sinalagmáticos. Ellos, como vimos, consisten en obligarse ambas partes, la activa a dar en el mutuo o a entregar en los demás casos, y la pasiva, a recibir.

1. Ahora bien, dejando para examinar en su momento, las objeciones prácticas o de hecho que el establecimiento de una obligación de recibir porta consigo, atendamos ahora solo a sus desajustes dogmáticos.

Previamente es menester fijar en quién normalmente recae la utilidad de los contratos reales. En el mutuo sin intereses y en el comodato, su utilidad es de la parte que recibe, vale decir, del mutuario y del comodatario. En el depósito es de la parte que entrega, o sea, del depositante. En el mutuo con interés es de ambas partes.

Es consecuente con ello que de antemano pueda calcularse el efecto que tiene la construcción de una obligación de recibir de la parte pasiva en los contratos que solo a ella son útiles, si es que la utilidad para el que debe recibir, por alguna razón de hecho que no interesa saber, ya no existe.

2. Así, pues, en los contratos que solo son útiles al que recibe, obligarlo a recibir parece contrario a una sana dogmática. Tal, como dijimos, ocurre:

i) En el mutuo sin interés, que sólo es útil al mutuario. Es consiguiente que en esta clase de mutuo, aquél puede devolver la cantidad recibida con anticipación al plazo pactado (artículo 1658 CCPer.). Por ende, una obligación suya de recibir, no acompañada, por cualquier razón, de la utilidad de hecho en recibir, se burla recibiendo y acto seguido devolviendo; eso equivale a directamente rehusar recibir; que incluso podría construirse como pago mediante una suerte de traditio brevi manu impropia en el momento de ir a recibir.

ii) En el comodato, con o sin plazo de restitución convenido, que solo interesa al comodatario, como éste entonces se encuentra obligado a "devolver el bien [...] después del uso para el que fue dado en comodato" (artículo 1738 No 5 CCPer.), con mayor razón debe entenderse que si la parte pasiva del contrato consensual ya no la necesita al tiempo de ir a recibirla, puede alegar este hecho para no recibirla, sin necesidad de probar tal hecho negativo. Si el comodato tuvo plazo de restitución, aún así podría aquella parte rehusar la recepción, con base en la regla del No 3 del artículo 1735 CCPer., según la cual el comodante no debe exigir la restitución del bien

dice: "En tout cas, la solution [sc. de la jurisprudencia], quelque contestable qu'elle soit pour des raisons indépendantes de la notion de contrat réel, demontre la volonté de la jurisprudence de conservar cette notion". 
"antes de haber servido al uso para el que fue dado en comodato", porque si pedir una restitución después de haber terminado el uso es un derecho del comodante, la de restituir en las mismas circunstancias es correlativamente una obligación del comodatario, así que él puede alegar que ha terminado o no tiene lugar el servicio para el cual necesitaba la cosa y devolverla acto seguido a la recepción, o simplemente repudiar ésta.

3. Vamos a los contratos no útiles a la parte que recibe, sino a la que entrega, como el depósito. Una obligación de recibir a cargo de la parte pasiva en él, no es dogmáticamente incorrecta. Tiene sentido establecerla, porque la parte activa podría querer asegurarse con anterioridad a la entrega, de que la parte pasiva no podrá rehusarse a recibir. Podría querer, en síntesis, asegurarse que su proyectado depósito va a tener lugar. Sin embargo, aquí debemos adelantar que carecería de sentido obligarlo a él a entregar, porque si, por regla general, en el depósito procede restituir "cuando lo solicite depositante"(artículos 1814 y 1830 CCPer.), aun cuando se fije un plazo para la restitución (artículo 1830 CCPer.), es consiguiente que él pueda entregar y acto seguido pedir la restitución, lo que equivale a rehusarse a entregar. Si es así, el contrato consensual de depósito no debe nunca ser bilateral, al carecer de sentido construir una obligación de entregar. Su examen queda, pues, postergado para el más general de los contratos consensuales unilaterales.

4. Pasemos, en fin, a los contratos útiles a ambas partes.

En el mutuo con intereses, que, en efecto, es útil al mutuante que da, con base en los intereses pactados, y al mutuante, en cuanto a la disposición de la cantidad que recibe, una obligación de recibir no carece de sentido. Es consistente con ello que el mutuario no pueda pagar la suma recibida con anterioridad al pago estipulado (artículo 1658 CCPer.).

En síntesis, pues, la construcción de los contratos consensuales como sinalagmáticos es dogmáticamente incongruente con respecto al mutuo sin interés, al comodato y el depósito. Solo tiene una cierta congruencia dogmática en el mutuo con interés.

Ahora bien, diseñar una reforma de derecho privado tan radical para un caso, no parece ni prudente ni razonable.

\section{EL EMPALME DOGMÁTICO DE LA OBLIGACIÓN DE ENTREGAR EN LOS CONTRATOS UNILATERALES Y DE RECIBIR EN EL UNILATERAL DE DEPÓSITO}

Veamos qué congruencia dogmática ofrecen estos contratos consensuales cuando se los quiera configurar tan sólo como unilaterales, vale decir, con obligación de dar o entregar, según el caso, en el mutuo con o sin intereses y el comodato, pero sin la contrapartida de una obligación 
de recibir; o con obligación de recibir en el depósito, sin una correlativa obligación de entregar.

1. En los contratos que sólo son útiles a la parte que recibe, como el mutuo sin intereses y el comodato con o sin plazo de restitución, un contrato consensual que obligue a la parte activa a dar o entregar, según el caso, tiene sentido para la contraparte precisamente interesada en recibir, que de esa manera se asegura la entrega por anticipado, una vez adoptada su decisión de requerir los fungibles que necesita en mutuo, o la especie que precisa usar, sin necesitar esperar a la efectiva tradición o entrega, única que en la operación concebida como real asegura su interés.

En los contratos que son útiles a la parte que entrega, como el depósito, un contrato consensual unilateral, con una obligación de la parte pasiva en orden a recibir también tiene sentido para la parte activa, interesada en conseguir la custodia de un cierto mueble, pues de esa manera se asegura la recepción desde que empezó su necesidad de entregar en custodia, sin que haya menester esperar la entrega para asegurarse aquélla.

En los contratos que son útiles a ambas partes, como el mutuo con intereses, en fin, nuevamente hay que declararlo con sentido para el que ha de recibir, que con él ve asegurado de su interés en precisamente recibir desde antes que tenga lugar la entrega.

2. Esta corrección dogmática corresponde a la misma corrección que se presenta en el contrato de promesa de un contrato real, merced al cual el promitente activo de un mutuo o comodato se obliga a dar o entregar, según el caso, o el promitente pasivo de un depósito, a recibir. Una promesa tal, concebida, pues, como unilateral, ya que solo una de sus partes se obliga a concluir el contrato real, es plenamente aceptada por la doctrina. Si es así, como la situación no cambia en los propuestos contratos consensuales, he ahí que estos también deben resultar plenamente aceptables. Por lo demás, tal es la solución del Código peruano.

Pero esta observación relativa a la promesa de contrato real nos consiente hacer una observación. Antes dijimos que la supresión de los contratos reales y su conversión en consensuales contiene dos conversiones: la del convenio causal no vinculante de aquellos en contrato, y la de su tradición o entrega perfeccionadoras en actos de cumplimiento del nuevo contrato. Ahora debemos agregar que también contiene una nueva conversión, la de la promesa unilateral misma de contrato real en contrato consensual sustitutivo del real. Se produciría así una suerte de fusión de la promesa de cada uno de los contratos reales con el convenio causal de la tradición o entrega perfeccionadora de los mismos.

En tales circunstancias, ¿por qué sustraer a las partes la disponibilidad del instrumento de la promesa (mejor, de la opción)? ¿por qué no permi- 
tirles que escojan ellas primero celebrar el contrato preparatorio y después el real, si les conviene y tienen interés en ellos; antes que forzarlas a siempre celebrar un único contrato consensual?

\section{DIFICULTADES PRÁCTICAS QUE OFRECEN LOS CONTRATOS CONSENSUALES SUSTITUTIVOS}

1. Una línea de argumentación en favor del reemplazo de los contratos reales por unos contratos consensuales se orienta en el sentido de proteger el interés de las personas que reciben, salvo con respecto al depósito, en que la protección va hacia la persona que entrega. Si alguien recibe una oferta de comodato real, y el oferente olvida después su oferta y rehúsa la entrega, eso puede causar muchos perjuicios al que aceptó la oferta porque necesitaba la cosa ofrecida, sin nada poder hacer contra el olvidadizo, que no estuvo obligado a entregar ${ }^{48}$. La verdad es que lo mismo puede acaecer cuando la iniciativa es adoptada por el que desea recibir cierta cosa en comodato, si la pide a alguien, quien acepta prestarla, y posteriormente olvida o desconoce su aceptación. Sea como fuere, que un perjuicio puede irrogarse al interesado en recibir una cosa en comodato, con la retractación anterior a la entrega por el que aceptó prestarla, eso es cierto. Además, tal esquema se puede generalizar para el mutuo y para el depósito, pero con respecto al interesado en que un mueble suyo sea recibido en custodia.

El remedio a tal situación, que sería el contrato preparatorio, no funciona bien -se dice-, porque, fuerza a la celebración de dos contratos, el preparatorio y el definitivo, en circunstancias de poder haber urgencia en recibir la cosa, o en entregarla en el caso del depósito. Y todavía se agrega que el interesado en conseguir la entrega, o la recepción, en el caso de depósito, suele inhibirse de exigir un contrato preparatorio a su contraparte, atendido que ésta ningún interés tiene en el contrato definitivo y presumiblemente prefiera quedar libre de poder no entregar, o sea de arrepentirse, hasta el momento en que, decidido a entregar, entregue efectivamente.

Examinemos cada uno de estos argumentos.

2. La argumentación concerniente al interés del que recibe, o del que entrega en el caso del depósito, es -ya lo reconocimos- verdadera. Pero también unilateral. Examinemos un comodato real. Una vez acordado, supongamos que la parte activa quiere entregar; al efecto, puede ser que la desafecte de algunos usos útiles para él; quizá deba desechar venderla a quien le ofreció comprarla; tal vez incurrió en algunos gastos para dejarla en condiciones de ser usada por el comodatario, etcétera. Llegado el momento

${ }^{48}$ Es una de las líneas adoptadas por la profesora Doyharçabal, en su informe citado en la nota*. 
de la entrega, la parte pasiva, alegando no necesitar ya la cosa, la rehúsa y se retira de todos modos muy agradecida. La parte activa nada puede hacer, salvo disgustarse. Como se ve, esta situación es la contrapartida de aquella de la parte pasiva que contaba con que le irían a entregar la cosa que pidió en comodato, y que a última hora le fue negada.

El problema es que si ahora suponemos un contrato consensual de comodato, la situación cambia para la parte pasiva en su favor, mas no sucede lo propio para la activa. Eso, por el hecho de que, como ya tenemos aceptado, tal contrato debe ser unilateral, en el sentido de solo obligar a entregar mas no a recibir y que, cuando también obligara a recibir, tal obligación sería sin dificultad alguna eludible por el comodatario. Así que el contrato consensual protegería el interés del comodatario interesado en recibir, pero no el del comodante, quien, aunque carente de interés en entregar cuando el contrato es real, el cual, además, no le presta utilidad alguna, empieza a tener interés en entregar, cuando es consensual, aunque siga haciendo defecto una utilidad para él. Ese interés consiste en cumplir su obligación, para no ser demandado ni tener que indemnizar perjuicios. La pregunta práctica es ésta: ¿quién accedería a celebrar un contrato consensual de comodato sabiendo que no bien ponga todo de su parte para cumplirlo, ello puede resultar inútil si el comodatario perdió su inicial interés en recibir y omite hacerlo? Ciertamente se podría establecer alguna suerte de responsabilidad para el comodatario constituido en mora de recibir -la cual no existe en el Código peruano-. Pero, dejando a un lado que esta norma no haría sistema interno con respecto a un contrato para el cual no está dicho que el comodatario tiene la obligación de recibir, ella, como quedó dicho, es fácilmente eludible: para evitar esta responsabilidad, el comodatario podría recibir y acto seguido devolver, alegando que cesó el uso para el cual la recibió, y el efecto dańoso para el comodante es el mismo que si no la hubiera recibido el comodatario.

El análisis conducido para el comodato se puede repetir con respecto a los demás contratos. El contrato consensual de depósito protege el interés del depositante que cuenta con que la cosa tendrá que serle recibida por el depositario; pero se desentiende del interés de éste, quien preparó todo para recibir la cosa en el momento acordado y a última hora no le fue entregada por el depositante, que ya no necesita su custodia. Y si se pensare en imponerle alguna responsabilidad, ella podría ser eludida con el expediente de entregar la cosa para acto seguido pedir su restitución, lo que es facultad arbitraria del depositante. Un mutuante, que distrajo dinero de otras operaciones lucrativas para cumplir con su obligación de darlo en préstamo al mutuario a fin de ganar los mejores intereses acordados, se encuentra con que éste ya no necesita la cantidad y se desiste de recibirla. 
El contrato consensual de mutuo protegió su interés cuando le aseguró la entrega, pero desprotege el interés del mutuante.

En los contratos reales, en cambio, ambas partes están en igualdad de condiciones con respecto al punto del perjuicio que puedan eventualmente sufrir al preparar la entrega y la recepción, que finalmente no se consumaron. Eso es inevitable y normal, y entra en la economía de todo contrato antes de perfeccionarse. En la práctica, también ha de ocurrir en el contrato consensual antes de llegarse al consenso, consenso que en los contratos de liberalidad como el comodato, el mutuo sin intereses o el depósito, la parte que se grava retardará y hará coincidir con la entrega, antes de aceptar quedar previamente ligado. ¿A título de qué aceptará tal cosa si el contrato no le reporta utilidad alguna y podría ocasionarle más de un problema?

3. No es mejor el argumento consistente en la economía que se consigue al eliminar la duplicidad de contratos representada por el preparatorio y el contrato definitivo, que normalmente será uno de opción. La opción de mutuo, comodato y depósito son, en efecto, consensuales ${ }^{49}$. Si hay urgencia en recibir o en entregar, en el caso del depósito, esa urgencia determinará que la entrega o la recepción sean pedidas de inmediato y que no haya plazo ni condición para celebrar en el futuro el contrato definitivo; de forma que, en la practica, éste funcionará como real, pues si se acepta dilación es que tanta urgencia no hubo. En cuanto a que la parte que se beneficia puede auto-inhibirse de exigir un contrato preparatorio a la contraparte, más auto-inhibición habrá cuando explícita o implícitamente ronde la amenaza de exigir responsabilidades si no se cumple el contrato consensual. ¿Quién estaría dispuesto a presentarse ante alguien para solicitarle el préstamo, supongamos de un automóvil, y, frente a las consultas del interlocutor, verse en la necesidad de advertirle que si consiente en prestarlo, quedará obligado a entregarlo en tantos días o a indemnizarle los perjuicios que le cause con su negativa de hacerlo? ¿Y quién estaría dispuesto a tolerar que el favor y la gracia que se le pide resulten sujetos a semejante responsabilidad y, en tales circunstancias, a consentir como comodante en el acto? Casi puede calcularse o pronosticarse que los contratos consensuales de que hablamos habrán de caer en desuso.

4. La proposición de tales contratos no toma en cuenta ciertas realidades modernas que aminoran los riesgos que algunos contratos puramente reales hacen correr a las partes que se benefician con él, y que con la sustitución se tratan de evitar. Nos referimos, en primer lugar, a la profesionalización, tal cual ocurre con las operaciones de crédito, que constituyen actividad

${ }^{49}$ Artículo 1425 en relación con los artículos 1649, 1730 y 1816 CCPer. 
normal del sistema bancario y financiero, o con los depósitos practicados por empresas de custodia, así los almacenes denominados "Warrants" y otros. En segundo lugar, nos referimos a la moderna legislación protectora de los consumidores

El aludido profesionalismo de la actividad crediticia y depositaria hace que quien respectivamente da o recibe no suela negar a última hora y de improviso la celebración del real, causando perjuicios arbitrarios al particular que pide el crédito o quiere depositar, si no hay una justa razón de hecho que lo impulse a ello. Si el cliente es solvente y tiene todos sus papeles en regla, el banco no le negará el crédito que al principio se manifestó dispuesto a otorgarle, arguyendo de que el contrato no se ha perfeccionado por la tradición; de lo contrario obraría arbitrariamente y aun en contra de sus propios intereses. En contrapartida, como antes de entregar el dinero querrá verificar bien los antecedentes del cliente, se rehusará a quedar obligado a prestar celebrando el contrato consensual y hará todo lo posible por acercarlo al acto real.

Enseguida, está la protección al consumidor. Las leyes concernientes suelen, en efecto, contener disposiciones que impiden a los proveedores discriminar a los consumidores ${ }^{50}$, así que aquéllos no podrían negar injustificadamente los servicios y productos de sus giros, una vez ofrecidos. Puede, en consecuencia, decirse que existe una suerte de deber legal de prestar el servicio o producto ofrecidos, que ciertamente ampara al cliente de retractaciones abusivas. Esto es enteramente aplicable a los servicios de depósito; pero también a las operaciones de crédito.

\section{X. ¿POR QUÉ TANTO INCIENSO AL CONSENSUALISMO?}

Nos formamos la impresión que el sacrificio de los contratos reales en el altar del consensualismo es un sacrificio a cierto mito. El consensualismo, como principio general, es algo más bien moderno. Los romanos, que inventaron los contratos consensuales, desconocidos en otros pueblos de la Antigüedad, y particularmente en el mundo helenístico, no pensaron en elevar el canon que los rige a la categoría de tal principio; lo propio

${ }^{50}$ Así, el artículo 3 letra c) de la Ley No 19.496, Sobre protección a los derechos de los consumidores (DO. de 7 de marzo de 1997), concede un derecho a los consumidores, de no ser discrimianados arbitrariamente por los proveedores. También el artículo 7B de la Ley de protección al consumidor (Perú), establecida merced al Decreto supremo $\mathrm{N}^{\circ}$ 039-2000, del Ministerio de Industria, Turismo, Integración y Negociaciones Comerciales Internacionales, cuyo texto único fue establecido por el Decreto legislativo No 716, publicado el 11 de diciembre de 2000, fulmina contra los proveedores una prohibición de discriminar a los consumidores. 
hicieron los medievales. La generalización del consensualismo fue obra del derecho natural moderno. Ya a Grocio, y a autores más filosofantes que juristas, como Pufendorf, Thomasius o Wolf, les pareció sólo conforme con el derecho natural de la razón que el consenso de dos sea suficiente, tanto para transferir el dominio como para obligarse, sin necesidad de artificios no naturales como la tradición o unas solemnidades. Aun así, no se atrevieron a sugerir la abolición de los contratos reales, porque se dieron cuenta que eso es imposible. En las modernas codificaciones quedó indirectamente consagrado el consensualismo como principio general del Derecho de contratos, cuando, en síntesis, para obligarse solo se pide que dos partes capaces consientan sin vicios sobre un objeto lícito movidas por una causa lícita. Como no se pide además que consientan bajo ciertas formas o con subsiguiente entrega o tradición, aquéllas y éstas permanecen como excepciones que deben ser expresamente establecidas.

Pero todos saben que de hecho no es así. Lo que aparenta ser principio general es en la práctica excepcional, y queda relegado al ámbito teórico. Son muchas las exigencias de formalidades de diversa naturaleza para un sinnúmero de actuaciones jurídicas que fulmina la ley ${ }^{51}$, y, cuando no es ésta la que las exige, es tanta la desconfianza social hacia la mera palabra dada, que son los propios particulares quienes las piden; de esta manera, en los hechos, el recurso a los acuerdos meramente consensuales queda reducido al ámbito de las relaciones jurídicas entre parientes y amigos, y aun así, para operaciones de poca monta.

Tememos, pues, que la conversión de los contratos reales en consensuales en la práctica sea más bien una conversión de tales contratos en solemnes, de los cuales hay un paso a los reales nuevamente; pues no es infrecuente que la parte activa, o la pasiva en el caso del depósito, antes de aceptar contratar, exijan un escrito, y que no se allanen a firmarlo mientras no haya traspaso de la cosa. O sea, más o menos como se hace hoy, porque, aun siendo reales los contratos, si presentan alguna envergadura patrimonial, siempre se ven cubiertos por un acto escrito, cuyo momento de suscripción suele coincidir con el momento del traspaso mismo de la cosa.

[Recibido el 20 de agosto y aprobado el 13 de septiembre de 2007].

${ }^{51}$ Sobre este tema, véase el exhaustivo recuento de formalidades exigidas que ofrece López Santa María, Jorge, Los contratos. Parte general ( $4^{a}$ edición, Santiago, Editorial Jurídica de Chile, 2005), I, $₫ 42$, pp. 255-264. 


\section{BIBLIOGRAFÍA}

Baudry-LaCantinerie, Gabriel, Traité théorique et pratique de Droit civil des obligations (3a edición, Paris, 1906).

Bürgerliches Gesetzbuch

Carbonnier, Jean, Derecho flexible. Para una sociología no rigurosa del Derecho (traducción de L. Díez-Picazo, Madrid, Tecnos, 1974).

Carbonnier, Jean, Droit civil, iv: Les obligations (6a edición, Paris, Presses Universitaires de France, 1969).

Chabas, François, Obligations: théorie genérale, en Mazeaud, Henri y Léon - Mazaud, Jean - Chabas, François, Leçons de Droit civil (Paris, Montchrestien, 1997), II, 1.

Código Civil de Cuba

Código Civil de Chile

Código civil de Holanda

Código Civil del Perú

Ghestin, Jacques, La formation du contrat, en Traité de Droit civil sous la direction de Jacques Ghestin (3a edición, Paris, Librairie Générale de Jurisprudence, 1999).

Guzmán Brito, Alejandro, De las donaciones. Conceptos y tipos (Santiago de Chile, LexisNexis, 2005).

GuZMÁn Brito, Alejandro, La estructura de la donación entre vivos y su emplazamiento sistemático en la jurisprudencia medieval y moderna y en la codificación, en Revista de Derecho de la Pontificia Universidad Católica de Valparaíso 25 (Valparaíso, 2004), pp. 199-267.

JOBARD-BACHELLIER, Marie-Noëlle, Existe-t-il encore des contrats réels en droit français? ou la valeur des promesses de contrat réel en droit positif, en Revue Trimestrelle de Droit Civil 84 (janvier-mars 1985) 1, pp. 1-62.

Larroumet, Christian, Droit civil (3a edición, Paris, Economica, 1996).

Ley de protección al consumidor (Perú), establecida merced al Decreto supremo $\mathrm{N}^{\circ}$ 039-2000, del Ministerio de Industria, Turismo, Integración y Negociaciones Comerciales Internacionales, cuyo texto único fue establecido por el Decreto legislativo No 716, publicado el 11 de diciembre de 2000.

Ley No 19.496, Sobre protección a los derechos de los consumidores (DO. de 7 de marzo de 1997).

Loi fédérale complétant le Code Civil suisse (Livre v: Droit des obligations), de 30 de marzo de 1911.

López Santa María, Jorge, Los contratos. Parte general (4a edición, Santiago, Editorial Jurídica de Chile, 2005), I.

Marty, Gabriel - Raynaud, Pierre, Droit civil (Paris, Sirey, 1962), II, 1: Les obligations.

Terré, François, - Simler, Philippe - Lequette, Yves, Droit civil. Les obligations (9a edición, Paris, Dalloz, 2005).

Travaux de la Commission de Réforme du Code Civil. Année 1947-1948 (Paris, Sirey, 1949). 